\title{
The value of travel time savings in freight transport: a meta-analysis
}

\author{
Jawaher Binsuwadan ${ }^{1,2}$ (D) $\cdot$ Gerard De Jong $^{1,3} \cdot$ Richard Batley $^{1} \cdot$ Phill Wheat $^{1}$
}

Accepted: 29 June 2021 / Published online: 19 July 2021

(c) The Author(s) 2021

\begin{abstract}
The value of freight travel time savings (VFTTS) is a monetary value that is considered an important input into cost-benefit analysis and traffic forecasting. The VFTTS is defined as the marginal rate of substitution between travel time and cost and may therefore differ across firms, time and countries. The paper aims to explain variations in the VFTTS by using the meta-analysis method. The analysis covers 106 monetary valuations extracted from 56 studies conducted from 1988 to 2018 in countries across the globe. The meta-analysis method determines the factors that have an impact on these VFTTS variations. The paper briefly introduces the VFTTS concept and describes the adopted meta-analysis methodology, wherein different meta-models are used in VFTTS estimations. The results highlight the necessity of including multiple explanatory variables to ensure adequate explanation of the VFTTS variations. The findings also show that GDP per capita, transport mode and type of survey respondent are statistically significant variables. The paper sheds some light on the variations, thereby advancing the understanding of each factor's effects on the VFTTS. Furthermore, meta-model outcomes are used to generate new values of travel time savings for different transport modes in freight transport, for several countries. These implied VFTTS can be used as benchmarks to assess existing evidence or provide new evidence to countries where no such values exist.
\end{abstract}

Keywords Meta-analysis - Values of travel time savings · Freight transport $\cdot$ Randomeffects model

Jawaher Binsuwadan

tsjbi@leeds.ac.uk

Gerard De Jong

G.C.Dejong@its.leeds.ac.uk

Richard Batley

R.P.Batley@its.leeds.ac.uk

Phill Wheat

p.e.wheat@its.leeds.ac.uk

1 Institute for Transport Studies, University of Leeds, Leeds LS2 9JT, UK

2 Department of Economics, Princess Nourah Bint Abdulrahman University, PO Box 84428, Riyadh, Saudi Arabia

3 Significance, Grote Marktstraat 47, 2511 BH The Hague, The Netherlands 


\section{Introduction}

The value of freight travel time savings (VFTTS) is an important input to cost-benefit analysis, in particular when comparing time-savings with other costs and benefits of a project. Traffic forecasting is another area in which VFTTS is used as an input (De Jong, 2008). Analysis of the VFTTS was introduced in the mid-1980s when an increase in the value of products and the quality of services was noted in commodity market (Zamparini and Reggiani 2007a). In both freight and passenger transport, the value of travel time savings (VTTS) is associated with maximising utility for firms and for passengers/ workers, respectively. This maximisation problem is based on microeconomic theory, and is typically implemented using willingness-to-pay surveys and behavioural models to measure the VTTS for people and/or commodities (Zamparini and Reggiani 2016). VFTTS is a key benefit of the majority of transport improvement in both freight and passenger transport. In cost-benefit analyses, the time savings account for about $80 \%$ of the monetary benefit of projects in total in the United Kingdom (Mackie 2001). The freight transport, time savings in European countries represent a vital part of this percentage which is approximately a third of the time benefits (Massiani 2003). Therefore, a precise estimate of the VFTTS is essential for transport policy and planning.

In the paper we would use the terminology VFTTS; however, we acknowledge that there is a debate about using VFTT or VFTTS (Daly and Hess 2019). We mean that the VFTTS is a value of unit whether is a gain or loss. The VFTTS is usually reported in monetary terms per hour, which reflects the larger time and distances associated with the freight sector, unlike the monetary unit per minute sometimes used in passenger transport. One major issue in studies on the VFTTS is the heterogeneity between these values due to the influence of the shipment size, the decision makers, the transport mode and the type of goods being shipped. A further difference is the choice of analysis method. Therefore, it is important to consider the heterogeneity between VFTTS estimated in different ways (De Jong 2008). This paper aims to address how study-specific characteristics and within-study differences can explain the observed variations in VFTTS reported in the literature. We draw on studies published in the academic literature as well as unpublished studies, such as government reports, $\mathrm{PhD}$ theses, conference papers and working papers. We substantially expand on the studies used in past metaanalyses of VFTTS. To achieve this aim, a meta-analysis framework is used to explain variations across studies.

Meta-analysis has been applied in a range of domains that have combined the results of various studies that address the same research question (Wampold et al. 2000). The technique can be defined as a statistical analysis of the results that have been analysed in previous empirical studies. The use of the meta-analysis technique in the social and behavioural sciences emerged in the 1970s. Glass (1976) was the first to use the term 'meta-analysis' for what has become a powerful tool in the social sciences (Bangert-Drowns 1986). Since that time, researchers from different fields have shown an increased interest in using the meta-analysis method. The main objective of metaanalysis studies is to evaluate and analyse the quantitative results of multiple individual studies (Cleophas and Zwinderman 2007). The now well-established meta-analysis method provides valuable statistical results that are more efficient than the results of primary studies, due to the aggregation of existing information and data that supports decision making. Moreover, this type of analysis increases the precision and limits bias to improve the reliability of the findings (Chalmers and Altman 1997). 
This paper contributes to the existing literature by performing an updated review of the VFTTS, which has only been reviewed in a few studies so far (Zamparini and Reggiani 2007a, De Jong 2008, Feo-Valero 2011), of which only the first contains a meta-regression. The present meta-analysis includes studies from around the world and applies statistical analysis to pool the values, unlike the meta-analysis conducted by Zamparini and Reggiani (2007a), which only used VFTTS studies from the United States and developed countries in Europe, and only considered the road and rail transport modes. Furthermore, the present study examines a substantial number of explanatory variables, such as gross domestic product (GDP) per capita, transport mode, type of survey respondent, and survey method, among others. An additional difference between this analysis and the previous analysis is that the present paper considers the panel nature of the data that contain several studies from different countries by estimating fixed and random-effects models in addition to ordinary least squares (OLS). Besides, the weighted least-squares (WLS) model is used for weighting each study by the number of observations or the sample size as a proxy of precision of the VFTTS. Therefore, different meta-models will be used to consider the heterogeneous dataset and to obtain more precise estimates. In addition, meta-model outcomes will be used to generate VFTTS for different countries to be compared with past results and predict other situations.

The remaining sections of the paper are as follows: Sect. 2 briefly discusses the concept of VFTTS, how it is calculated in the literature, its features and the data methods used to estimate it. Section 3 provides a brief review of the meta-analysis method in freight transport. Section 4 describes the data and search strategy. Section 5 presents the meta-model. In Sect. 6, the estimation results are reported and interpreted. Section 7 contains a conclusion and recommendations for future work.

\section{The concept of value of freight travel time savings}

The value of time concept was first studied by Becker (1965) who discussed the basic methods that were afterwards adopted to analyse the value of travel time in passenger and freight transport. Several other authors have proposed adjustments and enhancements to calculate this value (Johnson 1966, Oort 1969; DeSerpa 1971; Jara-Díaz 2000). In relation to freight specifically, VFTTS is defined as the monetary value which derives from a unit reduction in time which is needed to move goods between two locations ${ }^{1}$ (De Jong 2008).

Whereas the passenger is the decision maker in passenger transport, different decision makers, such as the shipper or the carrier, are involved in freight transport choices. The former considers the cost of the cargo while the latter considers the transport cost (Sambracos and Ramfou 2016). Variations in VFTTS are also caused by other factors, such as the method of collecting data, the mode of transport, the regions where the survey is conducted and the income of the countries (Zamparini and Reggiani 2016). In the literature, studies use different methods to derive VFTTS. The factor cost method values the time savings on the basis of data related to wage rates and vehicle costs. In this method, saving in the costs of labour and vehicles could be used for other shipments when the travel time is decreased (De Jong 2008). The second method is transport demand modelling, which is commonly

\footnotetext{
1 As opposed to valuing the movement of people in relation to passenger transport, for example.
} 
based on maximising utility in passenger transport and in practice also in freight transport (Sambracos and Ramfou 2016).

The theoretical derivation of the firm's VFTTS can be rationalised in terms of an optimisation problem, whereby the firm seeks to maximise utility, which is dependent on the price of the transported goods, wage rate, transport attributes and the firm's characteristic, subject to time and budgetary constraints (Zamparini and Reggiani 2007a). The act of choosing between alternative freight transport reveals the firm's VFTTS, and this reflects the price that the firm is willing to pay to reduce the time needed to move goods between two destinations (De Jong 2008). In translating this theory to an empirical model, some formulation of the logit model is typically adopted, wherein the utility to firm $j$ from transport alternative $i$ and the model is typically represented by the linear form:

$$
U_{i j}=\beta_{0} C_{i j}+\beta_{1} T_{i j}+\varepsilon_{i j}
$$

where $U_{i j}$ is the utility of firm $j$ derived by choosing a specific transport alternative $i$; $C_{i j}$ is the transport cost for firm $j$ in relation to alternative $i$; $T_{i j}$ is the travel time of firms $j$ in relation to alternative $i ; \alpha$ and $\beta$ are the estimated parameters for cost and travel time; and $\varepsilon_{i j}$ is the random error term with a continuous joint finite density function that represents unobserved attributes of the firm's utility (Kawamura 2000, Zamparini and Reggiani 2007a). Most studies in the literature used this method to estimate the VFTTS, which in most cases is derived from a linear and additive utility function, by dividing the marginal utility of time by the marginal utility of cost, as follows:

$$
\text { VETTS }=\beta_{t} / \beta_{c}
$$

where $\beta_{\mathrm{t}}$ and $\beta_{\mathrm{c}}$ are the marginal utilities of time and cost from the model. ${ }^{2}$ In behavioural models, data are obtained by using stated preference (SP) or revealed preference (RP) techniques (De Jong 2008). The difference between these two methods lies in the type of information that is collected. In the RP technique, the collected data reflects actual travel behaviour for shippers or carriers. In the SP technique, the collected data refers to hypothetical situations. These hypothetical scenarios consist of different alternatives and attribute values, depending on a study's objective, such as time and cost (Feo-Valero 2016).

\section{Meta-analysis methodology}

In the mid-1990s, the application of the meta-analysis method first appeared in transport research. This method evaluates existing information to draw an overall conclusion (Button 1995). Button (1995) assessed the use of meta-analysis methods in transport studies, the results of which gave encouragement to transport researchers to adopt such methods. In general, meta-analyses in transport studies adopt the regression model approach (Paulley et al. 2006). This approach enables large amounts of evidence to be analysed, allowing insights to be drawn on the best methodologies and datasets (Elvik 2005).

\footnotetext{
${ }^{2}$ Some models in the literature estimate the VTTS directly (models in willingness to pay space), but these have mainly been used in passenger (Train and Weeks 2005). Also, some models use non-linear utility specifications, but again this is mostly found in passenger transport (Hensher and Rose 2009).
} 
Thus, a meta-analysis aggregates the outcomes from several primary studies by analysing and regressing their findings on independent variables, such as the countries where the study is conducted, the study population and the method used. In transport studies, meta-analysis techniques have been conducted in various areas, including transport demand elasticities (Nijkamp and Pepping 1998; Kremers et al. 2002; Hensher 2008; Wardman and Shires 2003; Wardman 2012), road safety (Egan et al. 2003, Elvik 2003; De Blaeij et al. 2003), travel time reliability (Tseng et al. 2005; Carrion and Levinson 2012), soft transport policies (Möser and Bamberg 2008) and cost overruns (Odeck 2017).

A meta-analysis of studies investigating the value of travel time in passenger transport has been conducted several times by different authors (Wardman 1998, Wardman, 2001, Wardman, 2004, Zamparini and Reggiani 2007b; Shires and De Jong 2009; Abrantes and Wardman 2011; Wardman et al. 2016). However, few meta-analyses have considered studies investigating the freight value of travel time, with Zamparini and Reggiani (2007a) being the only published VFTTS meta-analysis study.

Zamparini and Reggiani (2007a) conducted the first published meta-analysis of VFTTS to explain variations in VFTTS estimates. The study collected 46 observations from different studies that were grouped by region: Northern Europe, North America and Southern Europe. The regression results revealed three significant coefficients: Northern Europe, rail transport, and GDP/capita. These significant results provided useful evidence regarding possible variations in these values due to differences in locations, modes, and the country's income level. The study only considered VFTTS per shipment per hour so that a common unit of measurement could be used. The exclusion of other units of measurement used in the studies from the meta-analysis could limit the number and range of values considered-making it more difficult to explain the variation and obtain significant coefficients. Drawing from the same basic methodology, the Zamparini and Reggiani (2007a) study employed an Ordinary Least Squares (OLS) regression to explain the variations in VFTTS. One major assumption underlying the OLS model is that the values are not correlated. However, VFTTS from the same country or study might be correlated, and thus the assumption will not hold in practice.

One question that needs to be asked, however, is whether these variables sufficiently explain the variation in VFTTS. Therefore, the analysis in this study is an attempt to determine the factors that explain the variance in estimated VFTTS by examining an extensive number of explanatory variables, such as the GDP per capita, transport mode, type of survey respondents, survey method, and other variables. This analysis updates the study from 2007 by explaining how these values vary over time, the countries investigated, and the methods used in the studies. Moreover, several studies that measure VFTTS were published after the Zamparini and Reggiani (2007a) meta-analysis was conducted and the number of studies estimating VFTTS is increasing as can be seen in Fig. 1

Therefore, the present study further develops these ideas by including as many values as possible and converting these values to a common unit. Additionally, our meta-analysis includes studies from countries all over the world, without restricting attention to specific regions or transport modes. Furthermore, this study considers the correlated nature of the dataset, which contains several studies from the same country. More specifically, the Weighted Least Squares and random-effects model will be estimated and compared to the OLS model. 


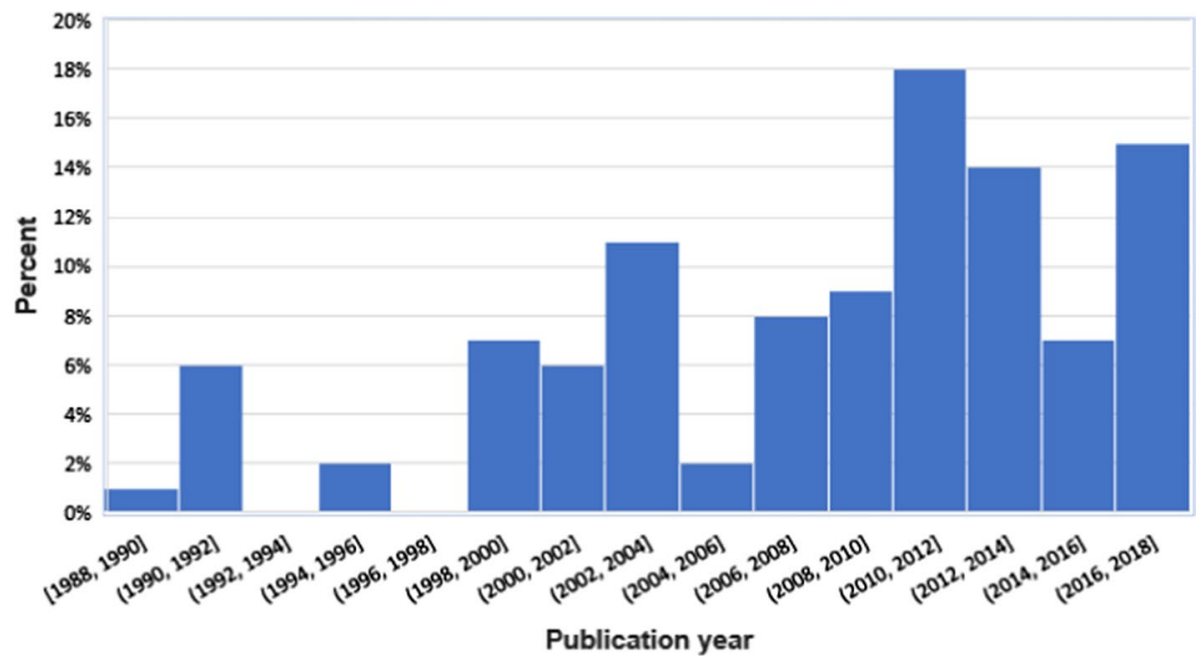

Fig. 1 Percentage of VFTTS studies in the meta-analysis dataset by year of publication

\section{Data and search method}

In the present meta-analysis, the dataset contains evidence from different countries about the valuations of freight travel time from the period 1988-2018. This dataset contains 106 monetary valuations collected from 56 studies. These studies consist of journal papers, government reports, $\mathrm{PhD}$ theses, conference papers and academic reports, both published and unpublished. While these 56 studies cover 25 countries across the world, the majority were conducted in Europe. The geographical scope and application context in each study is also considered. ${ }^{3}$

Because extracting data is an important stage in a meta-analysis, several inclusion and exclusion criteria were applied as follows: (1) only studies that used transport demand modelling to estimate the VFTTS were included to standardise the method and to obtain homogeneous dataset that are based on empirical evidence, thus studies using the factor cost method were excluded; (2) studies that only reported VFTTS for one or more specific types of the commodity transported, but not for all commodities, were excluded. ${ }^{4}$

In order to standardise the VFTTS units of measurement, which is the dependent variable, all the values were converted to a common unit: tonnes per hour. For studies where the unit is the shipment, these were converted to values per tonne. This conversion helps to obtain more comparable outcomes. An electronic search was used to find the studies, employing the following keywords: the 'value of travel time', 'freight transport', 'behavioural model', 'transport demand modelling', 'stated preference' and 'revealed preference'. Different search engines, such as Google and Google Scholar, were used to identify and select the studies. Searches were also conducted of specialist databases in transport studies,

\footnotetext{
3 The VFTTS collected from each study is for a specific county.Most of the studies focus on domestic flows with 73 observations and all remaining studies have international/export/import flows besides domestic flows; however, no significant effect was found for the spatial scope in the meta-model.

4 This exclusion is because very few studies contain VFTTS specifically for each commodity.
} 
Table 1 Descriptive statistics of VFTTS per tonne-hour and GDP per capita (in US\$ OF 2017)

\begin{tabular}{lll}
\hline VFTTS & VFTTS & GDP \\
\hline Number of observations & 106 & 106 \\
Minimum value & 0.00018 & 615 \\
Maximum value & 351 & 109,747 \\
Mean & 7.29 & 39,799 \\
Median & 1.14 & 39,265 \\
Standard deviation & 37.22 & 20,292 \\
\hline
\end{tabular}

Table 2 VFTTS and number of studies by country

\begin{tabular}{lllllr}
\hline Countries & Studies & VFTTS & Countries & Studies & VFTTS \\
\hline Australia & 3 & 4 & Korea & 1 & 2 \\
Belgium & 3 & 4 & Netherlands & 4 & 16 \\
Brazil & 1 & 3 & New Zealand & 1 & 2 \\
China & 1 & 4 & Norway & 2 & 3 \\
Colombia & 1 & 4 & Spain & 3 & 7 \\
Denmark & 2 & 2 & Sweden & 5 & 11 \\
Finland & 1 & 2 & Switzerland & 5 & 9 \\
France & 3 & 4 & Tanzania & 1 & 1 \\
Germany & 1 & 1 & Thailand & 1 & 2 \\
India & 1 & 1 & UK & 3 & 3 \\
Indonesia & 1 & 2 & USA & 7 & 11 \\
Italy & 5 & 8 & & & \\
\hline
\end{tabular}

Two studies in the dataset contain values for two countries, therefore the number of countries listed in this table is 23 instead of 25 countries

such as the Transport Database and EconLit. For 'grey' literature, conference websites were searched, and libraries were searched for pertinent theses and national studies related to VFTTS. No restriction is applied on language or date of publication. ${ }^{5}$

\section{Descriptive statistics}

The descriptive statistics of the VFTTS per tonne-hour and GDP per capita observations are shown in Table 1 . There is a very large variation regarding VFTTS that is included in the dataset, which has a mean of 7.29 US\$ and a standard deviation of $37.22 \$$. The minimum VFTTS across all the included studies is $0.00018 \$ 2017$ for road transport in Indonesia in 2011, while the maximum value is $350.59 \$ 2017$ for air transport in the Netherlands in 2014. As expected, the variation appears because our dataset contains values from different countries and transport modes. Additionally, the GDP per capita values are

5 The dataset contains few non-English studies. 
all expressed in dollars in the survey year. ${ }^{6}$ The values range from $615 \$$ for India in 2017 to $109,747 \$$ for Norway in the same year. The mean is equal to $39,799 \$ 2017$ and is close to the median 39,265\$2017 and the standard deviation is $20292 \$$.

Most studies report more than one VFTTS data point; the 56 studies that we selected provide a total of 106 data points, which are included in the meta-analysis. These data points, for example, derive from studies reporting VFTTS for different transport modes or by types of data. It can be seen from the data in Table 2 that almost half of the studies (48\%) yield one valuation, and most studies derive more than one VFTTS, particularly by transport mode and model type. The highest number of values derives from the De Jong et al. (2014) study with 6 observations segmented by the transport mode. VFTTS has been obtained for 25 different countries across the world. The Netherlands provides almost $15 \%$ of the values, followed by Sweden and the United States with approximately $10 \%$. Switzerland and Italy provide the next most observations, each with around $8 \%$ of the total values.

\section{Potential biases}

The possibility of biases in meta-analysis is often considered as a main criticism that should be explained and examined. Different ways to minimise the potential biases are applied when collecting the data and modelling them. The dataset includes published and unpublished studies collected from different sources to consider all the evidence and this difference will be tested in the meta-model. Furthermore, the coverage of non-English studies has been considered, as the dataset contains no restriction about the language. The VFTTS derived from the non-English studies are not significantly different from the English studies. The dataset has been reviewed by two authors independently and evaluated for correctness, plausibility and outlier values. The completeness of data has also been considered by starting with a number of different classes and if some studies could not be categorised into these detailed classes, for example, the commodity classes of the transported goods, we only applied core classifications. This application can help to reduce the potential biases by choosing to categorise the specifications in a way that minimises the non-mismatched studies.

\section{Publication bias}

A common type of descriptive analysis used frequently in meta-analysis is the funnel plot. This analysis is based on a visual graph that plots each estimated value from individual studies against their precision (Lin and Chu 2018). A funnel plot is used to detect the presence or absence of publication bias in meta-analysis. Hence, in the former case, the scatter plot shows an asymmetrical pattern, while in the latter case, the graph shows a symmetrical plot (Sterne and Egger 2001).

Selecting the precision variable could affect the pattern of this scatter graph. However, most studies used the standard error as an index of precise estimates, in addition to using the number of observations, sample size and inverse variance (Sterne and Egger, 2001). Furthermore, the estimated effect size in medical meta-analysis is usually plotted using the logarithmic scale to minimise data skewness (Higgins and Green 2011). Therefore, using the logarithmic scale

\footnotetext{
6 The GDP per capita data point was taken from World Bank statistics and all other variables were taken from the primary studies
} 


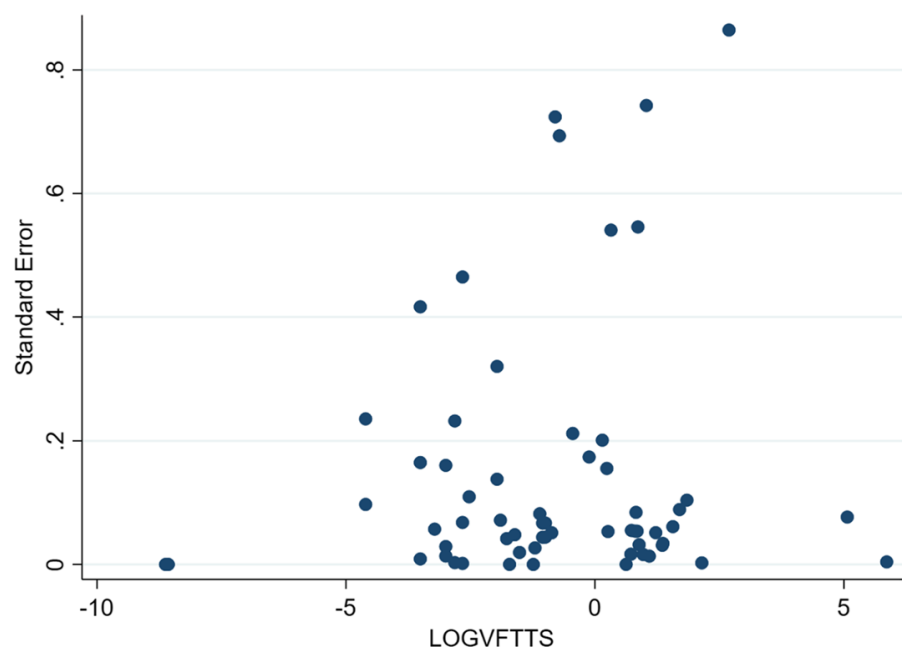

Fig. 2 Funnel plot (for studies that reported VFTTS standard error)

will help to ensure fewer skewed values versus using the values in their numerical scale (Higgins et al. 2008). In the funnel plot, we used the VFTTS in log transformation against the standard error as a proxy of precision. Therefore, values that are more precise are derived from studies that have a smaller standard error and vice versa. However, the VFTTS standard error was only reported in some of the studies included in the dataset.

Figure 2 provides the results obtained from the funnel plot of the VFTTS against their standard error. The funnel plot indicates a slightly skewed pattern, and this might be an indication of possible publication bias. However, this observed asymmetry pattern might be due to reasons other than publication bias, such as heterogeneity due to the studies' differences in characteristics, methodologies and sample sizes (Egger et al. 1997). The heterogeneity in the VFTTS is expected in the dataset and will be explained by applying the meta-regression model. The meta-model will, therefore, provide a more objective test for this asymmetry shape of the VFTTS estimates, and it will determine the variation between values.

\section{The meta-model}

The present study examines the monetary values of the freight travel time based on evidence drawn from international studies using a meta-analysis technique. The meta-regression model was conducted on 56 studies pertaining to this research subject. These studies cover a range of topics and countries, and a variety of methodologies. In general terms, the basic meta-analysis modelling structure is expressed by:

$$
\operatorname{VFTTS}_{j}=\alpha+\sum b_{i} x_{i j}+\varepsilon_{j}(j=1,2, \ldots L)(i=1,2, \ldots M)
$$

where VFTTS represents the value of freight travel time in the $\mathrm{j}$ - th study from a set of L studies. $\alpha$ is the intercept and $\mathrm{x}_{\mathrm{ij}}$ are the independent variables that could explain the variation across studies. $b_{i}$ are the coefficients of the $\mathrm{M}$ different study characteristics that are 
accounted for and $\varepsilon_{\mathrm{j}}$ is the error term (Button 2003). ${ }^{7}$ As in most VTTS meta-analysis studies we use as the preferred model specification a log transformation of the value of freight travel time in dollars per hour (the dependent variable) as well as for the right-hand-side variables ('double-logarithmic model'). For our own purposes, in studies that estimated the values in dollars, the values were converted to 2017 prices. In studies that estimated the values using their local currency, the values were converted to the dollar exchange rates and then to 2017 prices. The modelling equation used here is a development of the general framework given above, thus:

$$
\operatorname{VFTTS}_{j}=\tau \prod_{i=1}^{n} X_{i j}^{\alpha_{i}} e^{\sum_{r=1}^{p} \sum_{s=1}^{q p-1}} \beta_{r s} Z_{j r s}
$$

where $\mathrm{n}$ is the number of the continuous variables $\left(X_{i j}\right), \mathrm{p}$ is the number of categorial variables having $\mathrm{q}_{\mathrm{p}}$ categories $\left(Z_{j r s}\right) . \alpha_{i}$ are the interpreted as elasticities for the continuous variable and the exponential of $\beta_{j k}$ denotes the proportionate effect on a specific indicator relative to its omitted category (Wardman et al. 2016). The model is estimated first by using OLS. In terms of interpretation, using the double-logarithmic model implies that the estimated coefficients for the continuous independent variables can interpreted as elasticities (Benoit 2011).

\section{The weighted model}

Previous meta-analyses of the value of travel time generally assigns an equal weight to each data point or study; however, this leads to the risk of overweighting the values with lower precision or derived from using small sample size compared to studies that estimated more precise values or used bigger sample size (Stanley 2001). A recent meta-analysis of the VTTS by Wardman et al. (2016) applied another method by excluding the observations that had standard residuals outside the range of \pm 2 as an assumption of the poorest observations. Furthermore, they also included independent variables that are considered a proxy of the quality of the values, such as the number of values per study and the publication status. Therefore, weighting each study by the number of observations or by the sample size as a proxy of precision was also applied (De Blaeij et al. 2003, Odeck 2017) in our study.

The weighted model recognises that the estimated values from each study differ in precision; therefore, these values should be weighted with the number of observations or the sample size. ${ }^{8}$ In addition, as the VFTTS dataset comes from samples from different countries, heteroscedasticity can be naturally expected. Heteroscedasticity occurs when the variance of the error term varies (Greene 2000). To test for the heteroscedasticity, we used the standard Breusch-Pagan test, where the null hypothesis is constant variance (Breusch and Pagan 1979).

\footnotetext{
7 This formulation implies that every study only gives one VFTTS; however, for studies which estimate multiple values the model is expressed as: VFTTS $S_{j k}=\alpha+\sum b_{i k} x_{i j k}+\varepsilon_{j k}$ where VFTTS represents the k-th value for study $j(\mathrm{k}=1,2, \ldots \mathrm{K}$, with $\mathrm{K}$ being the number of estimated values in the study).

${ }^{8}$ Weighting the meta-model by the inverse-variance was also applied. The standard errors are calculated by using the delta method, which allows estimation of the standard error from the ratio parameters, such as in the case of the VFTTS (Daly et al. 2012). However, the inverse-variance weighting produced unexpected results for several independent variables, whether in the sign or magnitude of the coefficient.
} 


\section{The fixed and random-effects model}

A further development of the model formulation was to take account of panel effects in the data. This model considers the variations between observations that arise from the same group-level, such as the same study or the same country. The present dataset contains observations from different countries; however, the number of these observations is different between the countries. Therefore, the panel data is unbalanced, and the error term in this model contains two components. The first component is the error that is related to the group-specific effects. The second component is the error that is independent and normally distributed (Clark and Linzer 2015).

Two formulations were used to take account of panel effects, namely the fixed-effects model and the random-effects model. The former assumes that the first error term is fixed for every group, while the latter assumes that the group-specific effect is random and accounts for the between-study variance (Baltagi 2008). All models were estimated using STATA software (StataCorp 2015). On the basis of the described models in this section, the meta-model for this study, quantitative and indicator variables and estimation results will be discussed in Sect. 0 .

\section{The results}

This study focuses on explaining VFTTS variation reported in the literature by including the characteristics of the primary studies. This explanation can provide insights into the variation in VFTTS over time and countries, and the outputs can be used as a benchmark in evaluating new evidence and values. Therefore, insights presented by this paper can serve as a reference when reporting results from primary studies and when identifying structural and methodological issues in VFTTS research. In addition, meta-model outputs can produce new country specific values for different transport modes in freight transport. These implied values can be compared to the existing evidence or be used as new values where evidence is lacking. The model regresses VFTTS, which is the dependent variable, and the explanatory variables are GDP per capita in dollars and, a set of indicator variables, such as the type survey respondent (e.g. shippers or carriers), transport mode and other variables. A description of all the variables is presented below in Table 3.

In the regression, different functional forms are tested, including linear, double-log, and semi-log models, and the best result is obtained from the double logarithmic models. Zamparini and Reggiani (2007a) also use this specification in a regression analysis of European and American VFTTS studies and it has also been the preferred specification in many meta-analyses of the passenger VTTS. Thus, the coefficients of the quantitative variables will be interpreted as elasticities of the VFTTS to changes in the independent variable (notably GDP per capita). The results of the meta-model are estimated first by OLS for all the variables and reported in Table 4. Then, the WLS model is compared to the OLS model that includes only the significant variables, which can suffer from heteroscedasticity and this will be tested using the Breusch-Pagan test. The results of the WLS model are reported in Table 5 in the results section, noting that the number of observations is smaller $(n=87)$ than the total number of observations in Table 4 because some studies did not report the number of observations in their studies. Thus, these studies were removed from the model. Furthermore, OLS and random effect models were estimated for the significant variables 
Table 3 Definition of explanatory variables

\begin{tabular}{ll}
\hline Variable & Definition \\
\hline $\begin{array}{l}\text { Economic variable } \\
\text { LOGGDP }\end{array}$ & $\begin{array}{c}\text { The natural logarithm of GDP per capita in } 2017 \\
\text { Dollars }\end{array}$
\end{tabular}

Survey respondent indicator (omitted category $=$ shippers)

Carriers

Transport mode indicators (omitted category = road)

Rail

Sea

Air

Inland

Indicator variable that takes the value of 1 if VFTTS from carriers' choice; 0 otherwise

Indicator variable that takes the value of 1 if VFTTS for rail travel; 0 otherwise

Indicator variable that takes the value of 1 if VFTTS for sea travel; 0 otherwise

Indicator variable that takes the value of 1 if VFTTS for air travel; 0 otherwise

Indicator variable that takes the value of 1 if VFTTS for inland waterways transport; 0 otherwise

Experiment design Indicator (omitted category = efficient design)

Non-efficient

Indicator variable that takes the value of 1 if VFTTS from fractional factorial design, full factorial design, orthogonal design; 0 otherwise

Data type indicator (omitted category $=$ stated preference)

$\mathrm{RP}$

Indicator variable that takes the value of 1 if VFTTS estimated by using revealed preference data or pooled SP and RP data; 0 otherwise

Number of attributes indicator (omitted category $=$ two attributes)

Attributes

Indicator variable that takes the value of 1 if VFTTS from study contains more than 2 attributes; 0 otherwise

Time indicator (omitted category = year from 2000 to 2018)

Pre 2000

Indicator variable that takes the value of 1 if VFTTS from studies before 2000; 0 otherwise

Survey method indicator (omitted category = computer assisted personal interview (CAPI))

Non-CAPI

Indicator variable that takes the value of 1 if VFTTS from pen and paper, web and telephone survey method; 0 otherwise

Model estimation Indicator $*$ (omitted category $=$ standard models)

Advanced

Indicator variable that takes the value of 1 if VFTTS estimated by using advanced models (mixed logit model or latent class model); 0 otherwise

Publication status indicator (omitted category = published studies)

Unpublished

Indicator variable that takes the value of 1 if VFTTS estimated by unpublished studies; 0 otherwise

*The first model indicator is the standard models which include multinomial logit model, nested logit and ordered logit model. The second indicator is the advanced models, which contain mixed logit model and latent class model

Different coding system was used for survey method, model estimation and experiment design 
Table 4 OLS model for all variables (2017 prices, \$ pertonne/ hours)

\begin{tabular}{llll}
\hline Variables & Coefficient & $p$-value & Effect or elasticity \\
\hline Constant & -6.54 & 0.001 & \\
LOGGDP & 0.68 & 0.000 & 0.68 \\
Carriers & 1.35 & 0.002 & $+286 \%$ \\
Rail & -1.77 & 0.000 & $-83 \%$ \\
Sea & -2.08 & 0.004 & $-88 \%$ \\
Air & 2.68 & 0.002 & $+1359 \%$ \\
Inland & -2.03 & 0.002 & $-87 \%$ \\
Non-efficient & -1.02 & 0.029 & $-64 \%$ \\
Attributes & -0.19 & 0.795 & $-17 \%$ \\
Non-SP & 0.78 & 0.377 & $+118 \%$ \\
Non-CAPI & 0.01 & 0.622 & $+1 \%$ \\
Pre2000 & -0.32 & 0.394 & $-27 \%$ \\
Advanced & -0.44 & 0.273 & $-36 \%$ \\
Unpublished & 0.16 & 0.724 & $+17 \%$ \\
Model fit & $\mathrm{N}=106$ & $\mathrm{R}^{2}=0.58$ & \\
\hline
\end{tabular}

Table 5 OLS and WLS model (2017 prices, \$ per-tonne/ hours)

\begin{tabular}{llllll}
\hline Variables & \multicolumn{2}{l}{ OLS model } & & \multicolumn{2}{l}{ WLS model } \\
\cline { 2 - 3 } & Coefficient & $p$-value & & Coefficient & $p$-value \\
\hline Constant & -7.53 & 0.000 & & -7.21 & 0.005 \\
LOGGDP & 0.82 & 0.000 & & 0.77 & 0.002 \\
Carriers & 1.64 & 0.000 & & 1.25 & 0.016 \\
Rail & -1.74 & 0.000 & & -3.75 & 0.000 \\
Air & 3.11 & 0.001 & & 1.79 & 0.000 \\
Sea & -2.66 & 0.004 & & -3.92 & 0.001 \\
Inland & -2.27 & 0.010 & & -2.72 & 0.000 \\
Model fit & $\mathrm{N}=87$ & $\mathrm{R}^{2}=0.56$ & & $\mathrm{~N}=87$ & $\mathrm{R}^{2}=0.77$ \\
Breusch-Pagan test & Prob $=0.0003$ & & & Prob $=0.0000$ & \\
\hline
\end{tabular}

The table reports the results of the WLS model by using the square root of the number of observations as analytical weights

also and reported in Table 6. Concerning panel models, both the fixed and random-effects models were estimated; however, the random-effects model produced the best results and it is therefore reported here. This selection depends on the Hausman test, which is based on the differences between the estimators of the two models (Hausman 1978). Therefore, a higher value of the Hausman test indicates that the random-effects model is more appropriate than the fixed-effects model.

\section{Estimation discussion}

The results of the meta-model including all variables are reported in Table 4. The model is estimated by the OLS, where the natural logarithm of the VFTTS is the dependent variable. 
Table 6 OLS, fixed-effects and random-effects models (2017 prices, \$ per-tonne/ hours)

\begin{tabular}{|c|c|c|c|c|c|c|c|}
\hline \multirow[t]{2}{*}{ Variables } & \multicolumn{2}{|c|}{ OLS model } & \multicolumn{2}{|c|}{ Fixed-effects model } & \multicolumn{3}{|c|}{ Random-effects model } \\
\hline & $\begin{array}{l}\text { Coeffi- } \\
\text { cient }\end{array}$ & $p$-value & $\begin{array}{l}\text { Coeffi- } \\
\text { cient }\end{array}$ & $p$-value & $\begin{array}{l}\text { Coeffi- } \\
\text { cient }\end{array}$ & $p$-value & Effect or elasticity \\
\hline Constant & -7.06 & 0.000 & -15.6 & 0.059 & -8.03 & 0.001 & \\
\hline LOGGDP & 0.67 & 0.000 & 1.49 & 0.063 & 0.80 & 0.001 & 0.80 \\
\hline Carriers & 1.57 & 0.000 & 2.08 & 0.000 & 1.88 & 0.000 & $+555 \%$ \\
\hline Rail & -1.78 & 0.000 & -1.78 & 0.000 & -1.77 & 0.000 & $-0.83 \%$ \\
\hline Sea & -2.00 & 0.004 & -2.29 & 0.001 & -2.13 & 0.000 & $-0.88 \%$ \\
\hline Air & 2.26 & 0.005 & 2.71 & 0.000 & 2.67 & 0.000 & $+858 \%$ \\
\hline Inland & -2.08 & 0.001 & -3.39 & 0.000 & -2.89 & 0.000 & $-0.94 \%$ \\
\hline $\begin{array}{l}\text { Country vari- } \\
\text { ance }\end{array}$ & $\mathrm{Na}$ & $\mathrm{Na}$ & 0.69 & $\mathrm{Na}$ & 0.53 & $\mathrm{Na}$ & \\
\hline Model fit & $\mathrm{N}=106$ & $\mathrm{R}^{2}=0.51$ & $N=106$ & $\mathrm{R}^{2}=0.51$ & $\mathrm{~N}=106$ & $\mathrm{R}^{2}=0.51$ & \\
\hline
\end{tabular}

The independent variables are included in the model based on the effect of each variable in previous literature.

The first variable is the natural logarithm of the GDP per capita, which has a positive sign as expected. This effect was confirmed in the previous VFTTS meta-analysis because higher GDP per capita for a country leads firms to maintain their time and competitive power by using faster deliveries (Zamparini and Reggiani 2007a). However, the income variable in this dataset is expressed by the country's GDP per capita, which approximates the wage rate and price level in the country. In addition, transport mode indicators are considered in the model to demonstrate the impact of each mode on the VFTTS. It is expected that each transport mode will have a different VFTTS, particularly a high value for the road mode (and for air) is expected; 47 of the observations are related to road haulage. The coefficients for rail, sea, air and inland modes are compared to the road mode, which is the reference category.

The second set of indicator variables is the respondent in the survey. Investigating the difference between the decision makers in freight transportation is important, because in freight transportation, the valuation of travel time depends on who makes the decision (De Jong 2008). Therefore, the VFTTS will differ between decision makers, and it is expected that shippers might have lower values than carriers. A time indicator variable is also tested in the model to observe the changes in VFTTS over time. The expectation is that studies before 2000 might have higher values than more recent studies. One reason might be that most countries had an increase in their GDP before the year 2000 (Shires and De Jong 2009), but this should be picked up by GDP per capita. The number of attributes in each experiment is included in the model to investigate whether using attributes besides time and cost might result in higher values (Shams et al. 2017b, a). The data type SP or RP is included in the model to determine whether the effect of these data types on the VFTTS is significant (Wardman et al. 2016).

In the model, the estimation method and experimental design were taken into consideration as they were widely applied across VFTTS studies. Because there are different methods and designs, two categories are identified to limit the number of indicators. The general expectation is that the estimation models and the experiment design might not have a direct effect on the VFTTS, as this results was also obtained in the last passenger VTTS 
meta-analysis (Wardman et al. 2016). It can be seen from the model reported above in Table 4 that there is a variation in the VFTTS, and the model explains around 58\% of this variation. However, such variables as the data type (e.g. SP or RP), time variable, number of attributes, survey method, publication type and estimation model used in the individual studies, were found to be not significant in the model. As with Zamparini and Reggiani's (2007a) meta-analysis of the VFTTS, a substantial number of significant coefficients were obtained. Removal of all non-significant variables from the meta-model is applied in the next models. A detailed interpretation of the results will be undertaken for the meta-models with significant variables that influence the VFTTS.

The following meta-models regress the VFTTS on the significant explanatory variables from the previous model, and these are GDP per capita in dollars and, a set of indicator variables, such as the survey respondent (e.g. shippers or carriers) and transport mode. The experimental design indicator has a significant coefficient but was removed from the next models. This is because using different experimental designs (e.g. D-efficient design) should have an effect on the precision of the results with (a lower standard error), but not on the VFTTS estimate itself (Hess and Rose 2009; Bliemer and Rose 2011).

The model is estimated first by OLS, and the WLS model for studies reporting the number of observations. Because the estimated VFTTS might vary considerably in precision, there might be heteroscedasticity problems. Therefore, estimating the meta-model by OLS solely can lead to biased estimates of the coefficients. To solve this issue, the WLS model has been applied to weigh each VFTTS with a measure of its precision. Unfortunately, most VFTTS studies in the dataset did not report the standard errors, which are needed to compute the inverse variance weight. Therefore, we use the number of observations of a survey as a proxy of precision of the VFTTS in the analysis.

Table 5 shows the results of the OLS and WLS models and the results indicate that the estimated parameters from the weighted model are similar in sign and significance level to the OLS estimates; however, the magnitude of the transport mode indicator variables are noticeably different. In addition, a Breusch-Pagan test indicates that both the WLS and OLS model suffer from heteroscedasticity and therefore OLS with robust standard error is preferred compare to WLS model. This might be because of using the number of observations as analytical weights instead of using more conventional inverse variance weighting.

Relying on the OLS model only could affect the precision of the results due to the correlation between observations from the same country or study. Therefore, the meta-model is estimated by the random-effects model and compared to the OLS for all the observations. It can be seen from Table 6 below that there is variation in the VFTTS, and the model explains approximately $51 \%$ of this variation. The other $49 \%$ of the variation will depend on other characteristics not included in the model.

First, note that the signs of the coefficients across all models are similar with a slightly higher magnitude of all the coefficients in the random-effects model when compared to the OLS model. The Hausman test is used to compare the two estimators derived from the fixed and random-effects models, indicating better performance of the random-effects model. The results of the test gave a p-value of $0.6901\left(\chi^{2}=3.90\right)$, and the null hypothesis cannot be rejected. Therefore, the preferred model is the random-effects model. It accounts for the nature of the dataset that contains multiple values from the same country. From this point onward, the results produced by this model will be discussed.

A strong relationship between the value of travel time and income has been reported in the literature (Waters 1994). The income variable, which is a key influential variable, is estimated and has a positive relationship to the VFTTS. The estimated elasticity is close to unity and implies that a $1 \%$ increase in country income is associated with a $0.80 \%$ increase 
in the VFTTS, which is significantly different from zero at the 5\% level. This is slightly higher than the income elasticity of 0.68 estimated in the previous VFTTS meta-analysis (Zamparini and Reggiani 2007a). The role of income is definitely an important issue for administrators when developing transport infrastructure and project evolution (Waters 1994). Because an income elasticity of one for the VFTTS is often used in practice, we need to test this elasticity (Fosgerau 2005). The assumption of an income elasticity equal to one was tested and found to be not significantly different from unity with $p$-value $=0.416$ at the $5 \%$ significance level.

The first set of indicators included in the model distinguishes between different respondents of the survey-whether shipper or carrier. The carrier variable has a significant coefficient and a higher value than that of the shipper variable, which is the base category. This is expected because each respondent makes a different decision and has a different valuation of time (De Jong et al. 2014). The VFTTS will vary depending on the decision maker, and it is expected that shippers, who consider cargo costs, might have a lower travel time value than carriers, who consider transport costs, when they make trade-offs between time and cost (Halse et al. 2010; Shams et al. 2017b, a).

Furthermore, the transport mode indicators have a significant coefficient for all four indicators included in the model. As expected, the air mode has a higher value with an impact 14 times larger than the road omitted category, while the remaining indicators have lower values. The rail, sea and inland coefficients have a similar impact with approximately $83 \%, 88 \%$ and $94 \%$ lower values than the road category, respectively. This is in line with De Jong et al. (2014), who found that the VFTTS for rail, sea and inland have lower values than the VFTTS for the road mode, with roughly the same percentage. The results of the transport mode indicators have a similar coefficient sign as in passenger transport, with higher values for the air mode (Zamparini and Reggiani 2007b). The higher value for the air mode might be because the shipments usually contain high-value and time-sensitive products (Alkaabi and Debbage 2011). As the air variable in the random-effects model has a large influence, we tested and estimated the model without air observations. However, the model that includes an air variable provides a better fitting model, whereas other transport mode coefficients in both models were similar. Therefore, the random-effects model, reported in Table 6, will be used for calculating the implied VFTTS for various countries.

\section{Application of the estimated meta-model}

The estimated meta-model can yield an implied VFTTS for different countries, particularly those with no evidence or official values. The main purpose of estimating the implied values is to obtain the VFTTS for each country by different transport modes and types of respondents. The VFTTSs based on the meta-model will be compared with those in the literature to verify that the values are within the range of the reported VFTTS. Therefore, this comparison provides more confidence in the meta-model in predicting VFTTS for each country around the world. Furthermore, the estimated meta-model proposes a provisional value for countries without a VFTTS to be used in their transport projects.

Table 7 presents the VFTTS for different transport modes and refers to carriers or shippers in various countries. The selection of countries based on the country's GDP. The countries in the world with the biggest total GDP are included. In application, the randomeffects model estimation, reported in Table 6, was used. The GDP per capita in dollars of each country was ascertained from the 2017 statistical records of the World Bank statistics. 


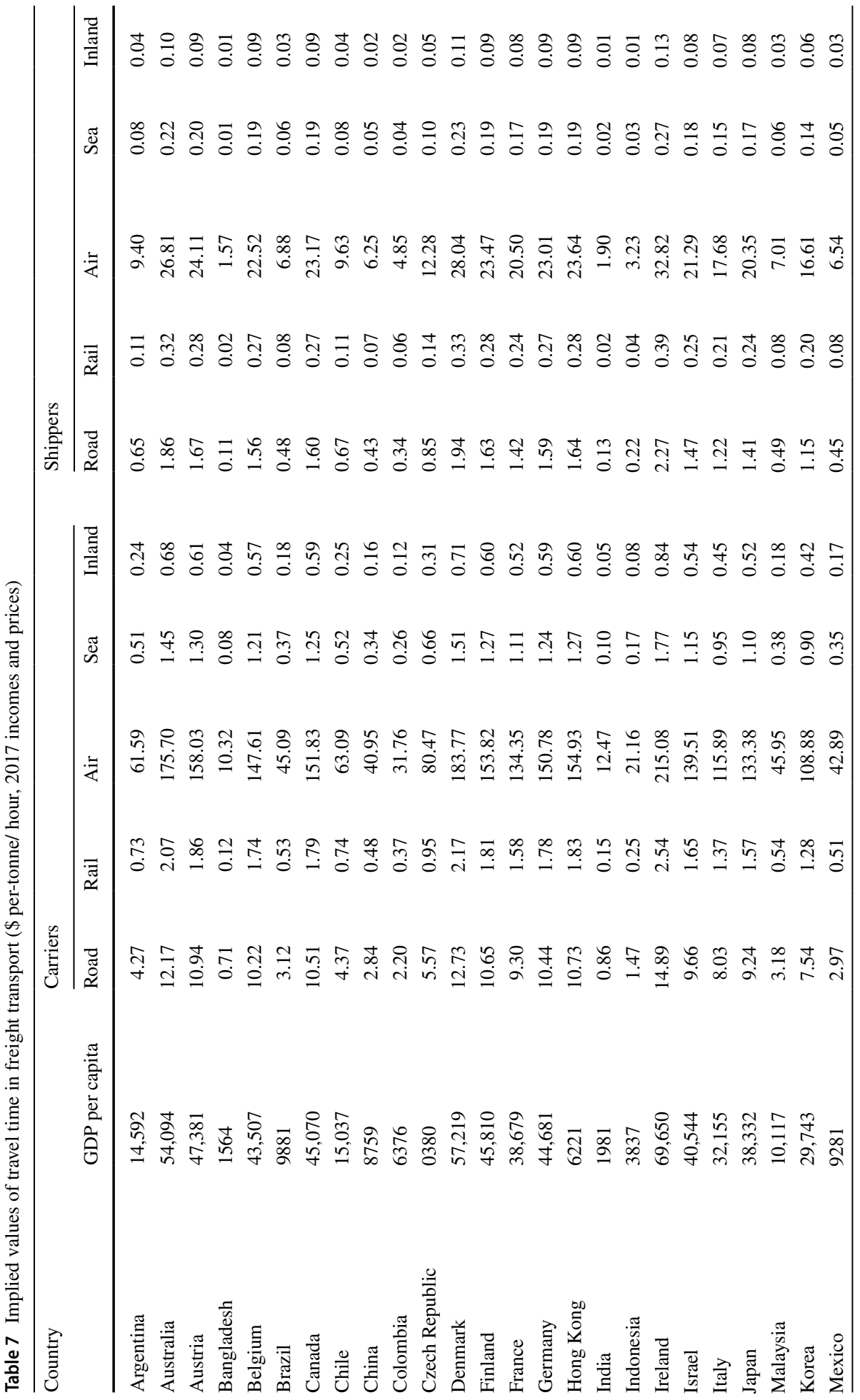




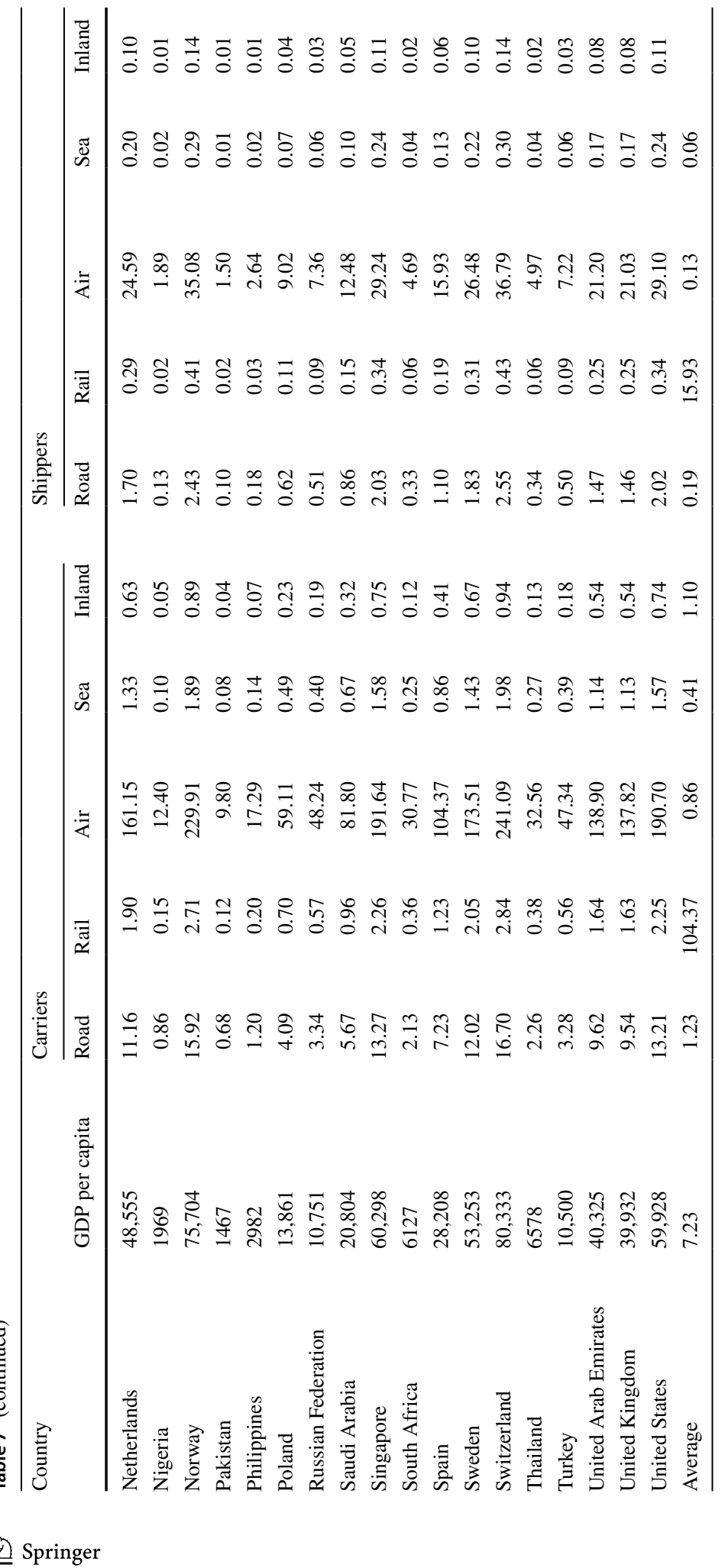


The variance in countries was set to zero, and each coefficient in the model was used to calculate specific mode values. This gives specific VFTTS for each country segmenting by five transport modes and two types of respondents.

Table 7 indicates that the implied values are in line with those obtained in previous studies and seem consistent with research that considered shippers values. These studies reported a higher VFTTS for roads than those derived for other transport modes, except air mode, which has the highest VFTTS (De Jong et al. 2004, De Jong et al. 2014). Large variations in the VFTTSs were observed for different modes and type of survey respondents, but these variances were expected because of the dissimilarities in GDP levels amongst the countries (Column 2, Table 7). Variations within each country occurred in accordance with transport mode and type of survey respondent, leading to the conclusion that the VFTTS for countries with high GDPs is higher than that of countries with low GDPs. This pattern was also observed in passenger transport, as was a higher VTTS for the air mode (Wardman et al. 2016). The average VFTTS of carriers on roads is 7.23 per- tonne/ hour, whereas that of shippers is 1.10 . These values are within the range reported in primary studies as measured by the $95 \%$ confidence interval.

\section{Conclusion}

This study has explained the variation in the value of freight travel time savings that is reported in the literature with respect to differences in study characteristics and methodologies, such as the income of the country, the transport mode and the type of survey respondent (e.g. carriers or shippers). A meta-analysis has been undertaken to achieve this which has considered within 56 primary studies. The paper presents estimation results for two models, in addition to the ordinary least squares (OLS) model, to explain the variation in VFTTS: the weighted least squares (WLS) and random-effects models (RE), which accounted for the multiple observations for the same country.

The meta-model found a variety of factors that affect the VFTTS leads to a better understanding of the variation. The income variable influenced how the decision-makers in freight transport valued their time, with a positive relationship between them. The estimated income elasticity from the meta-model of 0.67 (OLS), 0.77 (WLS) 1.49 (FE) and 0.80 (RE) was in the range of the reported elasticities in freight transport except for the fixed-effects model (Dunkerley et al. 2014). This income elasticity can be helpful, for example, in planning to build new or improved transport infrastructure, and it is considered the main factor driving VFTTS (Fosgerau 2005).

Furthermore, this meta-analysis offers several empirical findings to explain the variation in the VFTTS. First, it highlights the difference in the VFTTS for each transport mode, as demonstrated by the remarkable variation between the VFTTS in road and other modes included in the model. Second, it shows that VFTTS values differ significantly depending on the type of survey respondent, where carriers were found to have a significantly higher VFTTS than shippers, which supports the finding reported in studies that used data from both types of respondents (De Jong et al. 2014). Third, methodological factors between studies do not seem to explain VFTTS variations. Although our findings show that result, it is difficult to draw any conclusions on which methodology is the more appropriate to adopt in estimating the VFTTS. Finally, several of the estimated coefficients in our initial metamodel are not significantly different from zero, which needs further investigation by those 
interested in the estimated VFTTS, such as researchers, firms and policymakers. In particular, there are many insignificant coefficients for the variables related to data type (e.g. SP or $\mathrm{RP}$ ), survey method, year of publication, estimation method and number of attributes.

The findings of this study indicate that VFTTS has a large variation and that some explanatory variables remain to be examined. The VFTTS is likely to depend on studyspecific characteristics such as the type of goods, the trip distance and the country of the shipment. Therefore, the context should be considered when the VFTTS is used in forecasting, and caution is urged when using these values. To facilitate applying these values in developing the freight sector, it could be beneficial that future studies estimating the VFTTS further specify detailed features of the research design, context and appropriate segmentation (e.g. type of goods and transport mode). In addition, research on estimating VTTS in freight transport should preferably present all relevant information, especially data related to the precision of the estimates in the study to allow for in-depth and extensive meta-analyses. Furthermore, meta-model estimations were carried out for different countries around the world to derive implied VFTTSs for different transport modes and types of survey respondents, either for comparison with existing values or as initial reference for countries with missing VFTTSs.

Regarding the meta-model, we applied different models to obtain more accurate results by considering the heterogeneity between the VFTTS derived from various structural and methodological factors. This methodology can be improved in future research through investigations and evaluations of advanced meta-models from other fields, such as medicine, and the adoption of new techniques to be applied to this dataset. For example, all studies included in analyses can be weighted by their quality, with greater weight assigned to each data point derived from high-quality studies and vice versa. In studying quality assessment, researchers can use an assessment tool for scoring each study's quality on the basis of several criteria. The quality scores might assess the validity of the survey, the data type and estimation model used in a given research. Then, the quality score can be used in regression as an independent variable or as an analytical weight (Higgins and Green 2011, 2008). In addition, the standard error and its inverse-variance of the VFTTS can serve as indicators of value precision in the weighted model (Borenstein 2009).

\section{Declaration}

We confirm that this work is original and has not been published elsewhere, nor is it currently under consideration for publication elsewhere. As corresponding author, we confirm that the manuscript has been read and approved for submission by all the named authors.

\section{Appendix}

See Table 8 . 
Table 8 Studies included in the meta-analysis dataset

\begin{tabular}{|c|c|c|c|}
\hline Study no & References & Countries & Survey year \\
\hline 1 & Accent and Hague Consulting Group (1999) & United Kingdom & 1994 \\
\hline 2 & Arencibia et al. (2015) & Spain & 2012 \\
\hline 3 & Arunotayanun and Polak (2011) & Indonesia & 1999 \\
\hline 4 & Bergantino and Bolis (2008) & Italy & 2002 \\
\hline 5 & Bergantino et al. (2013) & Italy & 2008 \\
\hline 6 & Bergkvist (2001) & Sweden & 1991 \\
\hline 7 & Beuthe and Bouffioux (2008) & Belgium & 2004 \\
\hline 8 & Blauwens and Van de Voorde (1988) & Belgium & 1985 \\
\hline 9 & Bolis and Maggi (2003) & Italy and Switzerland & 1997 \\
\hline 10 & Brooks et al. (2012) & Australia & 2011 \\
\hline 11 & BVU and TNS Infratest (2014) & Germany & 2012 \\
\hline 12 & CGSP (2013) & France & 2011 \\
\hline 13 & Danielis et al. (2005) & Italy & 2002 \\
\hline 14 & De Jong et al. (2001) & France & 2000 \\
\hline 15 & De Jong et al. (2004) & Netherlands & 2002 \\
\hline 16 & De Jong et al. (2011) & Netherlands & 2004 \\
\hline 17 & De Jong et al. (2014) & Netherlands & 2010 \\
\hline 18 & Duan et al. (2017) & China & 2015 \\
\hline 19 & Feo et al. (2011) & Spain & 2006 \\
\hline 20 & Feo-Valero et al. (2016) & Spain & 2014 \\
\hline 21 & Fosgerau (1996) & Denmark & 1889 \\
\hline 22 & Fowkes (2006) & United Kingdom & 2004 \\
\hline 23 & Fowkes (2015) & United Kingdom & 2004 \\
\hline 24 & Fowkes et al. (2004) & United Kingdom & 2001 \\
\hline 25 & Fries et al. (2010) & Switzerland & 2008 \\
\hline 26 & Goenaga and Cantillo (2018) & Colombia & 2016 \\
\hline 27 & Gong et al. (2012) & USA & 2010 \\
\hline 28 & Hague Consulting Group (1992) & Netherlands & 1990 \\
\hline 29 & Halse and Killi (2012) & Norway & 2010 \\
\hline 30 & Halse et al. (2010) & Norway & 2008 \\
\hline 31 & INREGIA (2001) & Sweden & 1999 \\
\hline 32 & Johnson and De Jong (2011) & Sweden & 2001 \\
\hline 33 & Kang et al. (2010) & Korea & 2006 \\
\hline 34 & Kawamura (2000) & USA & 1999 \\
\hline 35 & Kawasaki et al. (2014) & Thailand & 2011 \\
\hline 36 & Kim et al. (2017) & New Zealand & 2014 \\
\hline 37 & Kurri et al. (2000) & Finland & 1998 \\
\hline 38 & Larranaga et al. (2017) & Brazil & 2015 \\
\hline 39 & Maggi and Rudel (2008) & Switzerland & 2003 \\
\hline 40 & Masiero and Hensher (2010) & Switzerland & 2008 \\
\hline 41 & Masiero and Hensher (2012) & Switzerland & 2003 \\
\hline 42 & Masiero and Rose (2013) & Switzerland & 2003 \\
\hline 43 & Miao (2014) & USA & 2013 \\
\hline 44 & Puckett and Hensher (2008) & Australia & 2005 \\
\hline
\end{tabular}


Table 8 (continued)

\begin{tabular}{llll}
\hline Study no & References & Countries & Survey year \\
\hline 45 & Rich et al. (2009) & Denmark and Sweden & 1996 \\
46 & Shams et al. (2017b, a) & USA & 2016 \\
47 & Shinghal and Fowkes (2002) & India & 1998 \\
48 & Smith (1999) & USA & 1995 \\
49 & Train and Wilson (2008) & USA & 2004 \\
50 & Vieira (1992) & USA & 1990 \\
51 & Widlert and Bradley (1992) & Sweden & 1992 \\
52 & Wigan et al. (2000) & Australia & 1998 \\
53 & Witlox and Vandaele (2005) & Belgium & 2003 \\
54 & Wynter (1995) & France & 1990 \\
55 & Zamparini et al. (2011) & Tanzania & 2008 \\
56 & Zotti and Danielis (2004) & Italy & 2002 \\
\hline
\end{tabular}

Acknowledgements The first author gratefully acknowledges the Princess Nourah bint Abdulrahman University for funding her $\mathrm{PhD}$ programme at the University of Leeds. The authors are grateful for the comments of two anonymous referees which enabled us to improve the paper.

\section{Declarations}

Conflict of interest On behalf of all authors, the corresponding author states that there is no conflict of interest.

Open Access This article is licensed under a Creative Commons Attribution 4.0 International License, which permits use, sharing, adaptation, distribution and reproduction in any medium or format, as long as you give appropriate credit to the original author(s) and the source, provide a link to the Creative Commons licence, and indicate if changes were made. The images or other third party material in this article are included in the article's Creative Commons licence, unless indicated otherwise in a credit line to the material. If material is not included in the article's Creative Commons licence and your intended use is not permitted by statutory regulation or exceeds the permitted use, you will need to obtain permission directly from the copyright holder. To view a copy of this licence, visit http://creativecommons.org/licenses/by/4.0/.

\section{References}

Abrantes, P.A., Wardman, M.R.: Meta-analysis of UK values of travel time: an update. Transp. Res. Part a: Policy Pract. 45, 1-17 (2011)

Alkaabi, K.A., Debbage, K.G.: The geography of air freight: connections to US metropolitan economies. J. Transp. Geogr. 19, 1517-1529 (2011)

Arencibia, A.I., Feo-Valero, M., García-Menendez, L., Román, C.: Modelling mode choice for freight transport using advanced choice experiments. Transp. Res. Part A: Policy Pract. 75, 252-267 (2015)

Baltagi, B: Econometric Analysis of Panel Data, John Wiley \& Sons. (2008)

Bangert-drowns, R. L.: Review of developments in meta-analytic method. American Psychological Association (1986)

Becker, G.S.: A theory of the allocation of time. Econ. J. 75(299), 493-517 (1965)

Benoit, K.: Linear regression models with logarithmic transformations. London School Econ. London 22, 23-36 (2011)

Beuthe, M., Bouffioux, C.: Analysing qualitative attributes of freight transport from stated orders of preference experiment. J. Transp. Econ. Policy (JTEP) 42, 105-128 (2008) 
Bliemer, M.C., Rose, J.M.: Experimental design influences on stated choice outputs: an empirical study in air travel choice. Transp. Res. Part a: Policy Pract. 45, 63-79 (2011)

Borenstein, M.: Introduction to Meta-Analysis. John Wiley \& Sons, Chichester (2009)

Breusch, T. S., Pagan, A. R.:A simple test for heteroscedasticity and random coefficient variation. Econom.: J. Econom. Soc. 1287-1294 (1979)

Button, K.: What can meta-analysis tell us about the implications of transport? Reg. Stud. 29, 507-517 (1995)

Button, K.: The potential of meta-analysis and value transfers as part of airport environmental appraisal. J. Air Transp. Manag. 9, 167-176 (2003)

Carrion, C., Levinson, D.: Value of travel time reliability: a review of current evidence. Transp. Res. Part a: Policy Pract. 46, 720-741 (2012)

Chalmers, I., Altman, D. G.: Systemic Reviews, BMJ publishing Group (1997)

Clark, T.S., Linzer, D.A.: Should I use fixed or random effects? Polit. Sci. Res. Methods 3, 399-408 (2015)

Cleophas, T.J., Zwinderman, A.H.: Meta-Analysis. Circulation 115, 2870-2875 (2007)

Daly, A., Hess, S.: VTT or VTTS: a note on terminology for value of travel time work. Transportation 47(3), 1-6 (2019)

Daly, A., Hess, S., de Jong, G.: Calculating errors for measures derived from choice modelling estimates. Transp. Res. Part b: Methodol. 46, 333-341 (2012)

de Blaeij, A., Florax, R.J., Rietveld, P., Verhoef, E.: The value of statistical life in road safety: a meta-analysis. Accid. Anal. Prev. 35, 973-986 (2003)

De Jong, G.: Value of freight travel-time savings. Handbook of Transport Modelling: 2nd Edition. Emerald Group Publishing Limited (2008)

de Jong, G., Kouwenhoven, M., Bates, J., Koster, P., Verhoef, E., Tavasszy, L., Warffemius, P.: New SPvalues of time and reliability for freight transport in the Netherlands. Transp. Res. Part e: Logistics Transp. Rev. 64, 71-87 (2014)

De Jong, G., Vellay, C. \& Houee, M.: A joint SP/RP model of freight shipments from the region Nordpas de Calais. In: Proceedings of the aet european transport conference, held 10-12 september, 2001, Homerton college, Cambridge, UK-CD-ROM, (2001)

De Jong, G. C., Bakker, S., Pieters, M., Wortelboer-Van Donselaar, P.: New values of time and reliability in freight transport in The Netherlands. The European Transport Conference. Strasbourg (2004)

Deserpa, A.C.: A theory of the economics of time. Econ. J. 81, 828-846 (1971)

Duan, L., Peng, Q., Tang, Y.: Railway shippers' heterogeneous preferences with random parameters latent class model. Transp. Res. Procedia 25, 416-424 (2017)

Dunkerley, F., Rohr, C., Daly, A.: Road traffic demand elasticities: a rapid evidence assessment (2014)

Egan, M., Petticrew, M., Ogilvie, D., Hamilton, V.: New roads and human health: a systematic review. Am. J. Public Health 93, 1463-1471 (2003)

Egger, M., Smith, G.D., Schneider, M., Minder, C.: Bias in meta-analysis detected by a simple, graphical test. BMJ 315, 629-634 (1997)

Elvik, R.: Effects on road safety of converting intersections to roundabouts: review of evidence from nonUS studies. Transp. Res. Record: J. Transp. Res. Board 1847, 1-10 (2003)

Elvik, R.: Introductory guide to systematic reviews and meta-analysis. Transp. Res. Record: J. Transp. Res. Board 1908, 230-235 (2005)

Feo-Valero, M., García-Menendez, L., Del Saz-Salazar, S.: Rail freight transport and demand requirements: an analysis of attribute cut-offs through a stated preference experiment. Transportation 43, 101-122 (2016)

Feo-Valero, M., García-Menendez, L., Garrido-Hidalgo, R.: Valuing freight transport time using transport demand modelling: a bibliographical review. Transp. Rev. 31, 625-651 (2011)

Fosgerau, M. Unit income elasticity of the value of travel time savings. 8th nectar conference, las palmas gc june. 2-4 (2005)

Fries, N., De Jong, G., Patterson, Z., Weidmann, U.: Shipper willingness to pay to increase environmental performance in freight transportation. Transp. Res. Record: J. Transp. Res. Board 2168, 33-42 (2010)

Glass, G.V.: Primary, secondary, and meta-analysis of research. Educ. Res. 5, 3-8 (1976)

Greene, W. H.: Econometric analysis 4th edition. International edition, pp. 201-215. New Jersey: Prentice Hall (2000)

Halse, A. H., Samstad, H., Killi, M., Fliigel, S. \& Ramjerdi, F.: Valuation of freight transport time and reliability (2010)

Hausman, J. A.: Specification tests in econometrics. Econom.: J. Econom. Soc. 1251-1271 (1978)

Hensher, D.A.: Assessing systematic sources of variation in public transport elasticities: some comparative warnings. Transp. Res. Part A: Policy Pract. 42, 1031-1042 (2008) 
Hensher, D.A., Rose, J.M.: Simplifying choice through attribute preservation or non-attendance: implications for willingness to pay. Transp. Res. Part e: Logistics Trans. Rev. 45, 583-590 (2009)

Hess, S., Rose, J. M.: Some Lessons in Stated Choice Survey Design. European Transport Conference. Citeseer (2009)

Higgins, J. P., Green, S.: Cochrane handbook for systematic reviews of interventions (2008)

Higgins, J.P., Green, S.: Cochrane Handbook for Systematic Reviews of Interventions. John Wiley \& Sons (2011)

Higgins, J.P., White, I.R., Anzures-Cabrera, J.: Meta-analysis of skewed data: combining results reported on log-transformed or raw scales. Stat. Med. 27, 6072-6092 (2008)

Jara-Díaz, S.R.: Allocation and valuation of travel time savings. Handb. Transp. 1, 303-319 (2000)

Johnson, D. \& De Jong, G.: Shippers' response to transport cost and time and model specification in freight mode and shipment size choice. International Choice Modelling Conference 2011, (2011)

Johnson, M.B.: Travel time and the price of leisure. Econ. Inquiry 4, 135-145 (1966)

Kawamura, K.: Perceived value of time for truck operators. Transp. Res. Record: J. Transp. Res. Board 1725, 31-36 (2000)

Kremers, H., Nijkamp, P., Rietveld, P.: A meta-analysis of price elasticities of transport demand in a general equilibrium framework. Econ. Model. 19, 463-485 (2002)

Kurri, J., Sirkiä, A., Mikola, J.: Value of time in freight transport in Finland. Transp. Res. Record: J.Transp. Res. Board 1725, 26-30 (2000)

Larranaga, A.M., Arellana, J., Senna, L.A.: Encouraging intermodality: a stated preference analysis of freight mode choice in Rio Grande do Sul. Transp. Res. Part a: Policy Pract. 102, 202-211 (2017)

Lin, L., Chu, H.: Quantifying publication bias in meta-analysis. Biometrics 74, 785-794 (2018)

Mackie, P., Jara-Diaz, S., Fowkes, A.: The value of travel time savings in evaluation. Transp. Res. Part E: Logistics Transp. Rev. 37, 91-106 (2001)

Massiani, J.: Benefits of travel time savings for freight transportation: beyond the costs (2003)

Möser, G., Bamberg, S.: The effectiveness of soft transport policy measures: a critical assessment and meta-analysis of empirical evidence. J. Environ. Psychol. 28, 10-26 (2008)

Nijkamp, P., Pepping, G.: Meta-analysis for explaining the variance in public transport demand elasticities in Europe. J. Transp. Stat. 1, 1-14 (1998)

Odeck, J.: Variation in cost overruns of transportation projects: an econometric meta-regression analysis of studies reported in the literature. Transportation, 1-24 (2017)

Oort, C. J.: The evaluation of travelling time. J. Transp. Econ. Policy, 279-286 (1969)

Paulley, N., Balcombe, R., Mackett, R., Titheridge, H., Preston, J., Wardman, M., Shires, J., White, P.: The demand for public transport: the effects of fares, quality of service, income and car ownership. Transp. Policy 13, 295-306 (2006)

Sambracos, E., Ramfou, I.: Do freight transport time savings translate to benefit for transport consuming companies? Int. J. Bus. Sci. Appl. Manage. (IJBSAM) 11, 2-11 (2016)

Shams, K., Asgari, H., Jin, X.: Valuation of travel time reliability in freight transportation: a review and meta-analysis of stated preference studies. Transp. Res. Part a: Policy Pract. 102, 228-243 (2017a)

Shires, J.D., de Jong, G.C.: An international meta-analysis of values of travel time savings. Eval. Program Plann. 32, 315-325 (2009)

Stanley, T.D.: Wheat from chaff: Meta-analysis as quantitative literature review. J. Econ. Perspect. 15, 131-150 (2001)

Statacorp, L.: Stata statistical software: release 14.[computer program]. College Station, TX: StataCorp LP (2015)

Sterne, J.A., Egger, M.: Funnel plots for detecting bias in meta-analysis: guidelines on choice of axis. J. Clin. Epidemiol. 54, 1046-1055 (2001)

Train, K., Weeks, M.: Discrete choice models in preference space and willingness-to-pay space. Applications of simulation methods in environmental and resource economics. Springer (2005)

Tseng, Y., Rietveld, P., Verhoef, E.: A Meta-Analysis of Valuation of Travel Time Reliability. Colloquium Vervoersplanologisch Speurwerk. Rotterdam, Netherlands (2005)

Wampold, B.E., Ahn, H., Kim, D.: Meta-analysis in the social sciences. Asia Pac. Educ. Rev. 1, 67-74 (2000)

Wardman, M.: The value of travel time: a review of British evidence. J. Transp. Econ. Policy, 285-316 (1998)

Wardman, M.: A review of British evidence on time and service quality valuations. Transp. Res. Part E: Logistics Transp. Rev. 37, 107-128 (2001)

Wardman, M.: Public transport values of time. Transp Policy 11, 363-377 (2004) 
Wardman, M.: Review and meta-analysis of UK time elasticities of travel demand. Transportation 39, 465-490 (2012)

Wardman, M., Chintakayala, V.P.K., de Jong, G.: Values of travel time in Europe: review and metaanalysis. Transp. Res. Part a: Policy Pract. 94, 93-111 (2016)

Wardman, M. \& Shires, J.: Review of fares elasticities in Great Britain (2003)

Waters, W. G.: The value of travel time savings and the link with income: implications for public project evaluation. Int. J. Trans. Econ./Rivista Int. di economia dei Trasp., 243-253 (1994)

Wheat, P., Batley, R.: Quantifying and decomposing the uncertainty in appraisal value of travel time savings. Transp. Policy 44, 134-142 (2015)

Zamparini, L., Reggiani, A.: Freight transport and the value of travel time savings: a meta-analysis of empirical studies. Transp. Rev. 27, 621-636 (2007a)

Zamparini, L., Reggiani, A.: Meta-analysis and the value of travel time savings: a transatlantic perspective in passenger transport. Netw. Spat. Econ. 7, 377 (2007b)

Zamparini, L., Reggiani, A.: The value of travel time in passenger and freight transport: an overview. Policy analysis of transport networks. Routledge (2016)

\section{Further references (List of studies included in the meta-analysis)}

Accent, Research \& Group, H. C.: The value of time on UK roads. AHCG The Hague, Netherlands (1999)

Arunotayanun, K., Polak, J.W.: Taste heterogeneity and market segmentation in freight shippers' mode choice behaviour. Transp. Res. Part E: Logistics Transp. Rev. 47, 138-148 (2011)

Bergantino, A.S., Bierlaire, M., Catalano, M., Migliore, M., Amoroso, S.: Taste heterogeneity and latent preferences in the choice behaviour of freight transport operators. Transp. Policy 30, 77-91 (2013)

Bergantino, A.S., Bolis, S.: Monetary values of transport service attributes: land versus maritime ro-ro transport. an application using adaptive stated preferences. Marit. Policy Manag. 35, 159-174 (2008)

Bergkvist, E.: The value of time and forecasting of flowsin freight transportation (2001)

Blauwens, G., Van De Voorde, E.: The valuation of time savings in commodity transport. Int. J. Transp. Econ./Rivista Int. di Econ. dei Trasp., 77-87 (1988)

Bolis, S., Maggi, R.: Logistics strategy and transport service choices: an adaptive stated preference experiment. Growth Chang. 34, 490-504 (2003)

Brooks, M.R., Puckett, S.M., Hensher, D.A., Sammons, A.: Understanding mode choice decisions: a study of Australian freight shippers. Marit. Econ. Logistics 14, 274-299 (2012)

Bvuandtns: Entwicklung eines Modells zur Berechnung von modalen Verlagerungen im Güterverkehr für die Ableitung konsistenter Bewertungsansätze für die Bundeverkehrswegeplanung. Bundesministerium für Verkehr und digitale Infrastruktur (2014)

Cgps: L'évaluation socio-économique des investissements publics, rapport du commissariat général à la stratégie et à la prospective. La Documentation Française, Paris (2013)

Danielis, R., Marcucci, E., Rotaris, L.: Logistics managers' stated preferences for freight service attributes. Transp. Res. Part E: Logistics Transp. Rev. 41, 201-215 (2005)

De Jong, G., Burgess, A., Tavasszy, L., Versteegh, R., De Bok, M., Schmorak, N.: Distribution and modal split models for freight transport in The Netherlands. In: Proceedings of the 2011 European Transport Conference, Association for European Transport. On the generalized cost-demand elasticity of intermodal container transport, 2011.

Feo, M., Espino, R., Garcia, L.: An stated preference analysis of Spanish freight forwarders modal choice on the south-west Europe Motorway of the Sea. Transp. Policy 18, 60-67 (2011)

Fosgerau, M: Freight traffic on the Storebælt fixed link. Transportation planning methods. In: Proceedings of Seminar e Held at the Ptrc European Transport Forum, Brunel university, England 2-6 September 1996. Volume pp. 404-2, 1996

Fowkes, A.S.: Improving the Understanding of the Concept of the 'Reliability Ratio' for Freight. International Association for Travel Behaviour Research Windsor, UK (2015)

Fowkes, A.S., Firmin, P.E., Tweddle, G., Whiteing, A.E.: How highly does the freight transport industry value journey time reliability - and for what reasons? Int. J. Log. Res. Appl. 7, 33-43 (2004)

Fowkes, T.: The design and interpretation of freight stated preference experiments seeking to elicit behavioural valuations of journey attributes. Transp. Res. Part B: Methodol. 41, 966-980 (2006)

Goenaga, B., Cantillo, V.: Willingness to pay for freight travel time savings: contrasting random utility versus random valuation. Transportation 47, 1-32 (2018)

Gong, Q., Miao, Q., Wang, B. X.: Assessing public benefits and costs of freight transportation projects: measuring shippers'value of delay on the freight system (2012) 
Hague Consulting Group, R. T. C. A. N.: De reistijd-waardering in het goederenvervoer, Rapport Hoofdonderzoek, Report 142-1 for Rijkswaterstaat, Dienst Verkeerskunde, HCG, The Hague (1992)

Halse, A. H., Killi, M.: Values of transport time and reliability for railway freight (2012)

Inregia: Tidsvärden och transportkvalitet-INREGIA: s studie av tidsvärden och transportkvalitet för godstransporter 1999. Underlagsrapport till Samplan (2001)

Kang, K., Strauss-Wieder, A., Eom, J.K.: New approach to appraisal of rail freight projects in South Korea: using the value of freight transit time savings. Transp. Res. Rec. 2159, 52-58 (2010)

Kawasaki, T., Hanaoka, S., Nguyen, L.X.: The valuation of shipment time variability in Greater Mekong Subregion. Transp. Policy 32, 25-33 (2014)

Kim, H.-C., Nicholson, A., Kusumastuti, D.: Analysing freight shippers' mode choice preference heterogeneity using latent class modelling. Transp. Res. Procedia 25, 1109-1125 (2017)

Maggi, R., Rudel, R: The value of quality attributes in freight transport: evidence from an SP-experiment in Switzerland. Recent Developments in Transport Modelling: Lessons for the Freight Sector. Emerald Group Publishing Limited (2008)

Masiero, L., Hensher, D.A.: Analyzing loss aversion and diminishing sensitivity in a freight transport stated choice experiment. Transp. Res. Part A: Policy Pract. 44, 349-358 (2010)

Masiero, L., Hensher, D.A.: Freight transport distance and weight as utility conditioning effects on a stated choice experiment. J. Choice Model. 5, 64-76 (2012)

Masiero, L., Rose, J.M.: The role of the reference alternative in the specification of asymmetric discrete choice models. Transp. Res. Part E: Logistics Transp. Rev. 53, 83-92 (2013)

Miao, Q.: Measuring the Value of Time in Highway Freight Transportation (2014)

Puckett, S.M., Hensher, D.A.: The role of attribute processing strategies in estimating the preferences of road freight stakeholders. Transp. Res. Part E: Logistics Transp. Rev. 44, 379-395 (2008)

Rich, J., Holmblad, P.M., Hansen, C.: A weighted logit freight mode-choice model. Transp. Res.Part E: Logistics Transp. Rev. 45, 1006-1019 (2009)

Shams, K., Jin, X., Fitzgerald, R., Asgari, H., Hossan, M.: Value of reliability for road freight transportation: evidence from a stated preference survey in Florida. Transp. Res. Rec. 2610, 35-43 (2017b)

Shinghal, N., Fowkes, T.: Freight mode choice and adaptive stated preferences. Transp. Res. Part E: Logistics Transp. Rev. 38, 367-378 (2002)

Smith, B.: The good/leisure tradeoff and the value of travel time savings. Road Trans. Res. 8, 74 (1999)

Train, K., Wilson, W.W.: Estimation on stated-preference experiments constructed from revealed-preference choices. Transp. Res. Part B: Methodol. 42, 191-203 (2008)

Vieira, L. F. M. 1992. The Value of Service in Freight Transportation. Massachusetts Institute of Technology (1992)

Widlert, S., Bradley, M.: Preferences for Freight Services in Sweden. Sixth World Conference in Transport Research, Lyon, France (1992)

Wigan, M., Rockliffe, N., Thoresen, T., Tsolakis, D.: Valuing long-haul and metropolitan freight travel time and reliability. J. Transp. Stat. 3, 83-89 (2000)

Witlox, F., Vandaele, E.: Determining the monetary value of quality attributes in freight transportation using a stated preference approach. Transp. Plan. Technol. 28, 77-92 (2005)

Wynter, L. M.: Stated Preference Survey for Calculating Values of Time of Road Freight Transport in France. Transportation research record (1995)

Zamparini, L., Layaa, J., Dullaert, W.: Monetary values of freight transport quality attributes: a sample of Tanzanian firms. J. Transp. Geogr. 19, 1222-1234 (2011)

Zotti, J. \& Danielis, R.: Freight transport demand in the mechanics' sector of Friuli Venezia Giulia: the choice between intermodal and road transport (2004)

Publisher's Note Springer Nature remains neutral with regard to jurisdictional claims in published maps and institutional affiliations.

Jawaher Binsuwadan is a PhD student at the Institute for Transport Studies, University of Leeds. She is a lecturer at the Department of Economics, Princess Nourah Bint Abdulrahman University, Riyadh. She holds a MSc degree in Economics from King Saud University, Riyadh. Her doctoral research focuses on the application of meta-analysis to advance transport project appraisal.

Gerard De Jong is Director of Significance BV in The Netherlands and Research Professor at the Institute for Transport Studies, University of Leeds. He studied spatial economics and obtained a PhD in 
econometrics in 1989. He has worked on many international, national and regional model systems in passenger and freight transport.

Richard Batley is Professor of Transport Demand \& Valuation at the Institute for Transport Studies, University of Leeds. With a disciplinary background in transport economics, Richard's specialist expertise covers two related areas: first, valuing qualitative aspects of travel (e.g. journey time, punctuality and comfort) in monetary terms, and second, forecasting the impacts of changes in these qualitative aspects on the demand for travel. Richard has operated mainly at the interface between academe and public policy. His work has been reported to senior public servants and politicians and has been adopted within official policy and practitioner guidance issued to transport operators and scheme promoters.

Phill Wheat is an Associate Professor at the Institute for Transport Studies, University of Leeds. He has a background in economics and applied econometrics and has a primary area of interest of analysis of transport performance, costs and demand and how these are influenced by the competitive, market structure and institutional factors within transport markets. His work is a mixture of applied econometric analysis, development of econometric performance measurement techniques and regulatory economics. 